\title{
PERANCANGAN KARAKTER VISUAL SITI WALIDAH SEBAGAI PAHLAWAN PEREMPUAN INDONESIA DALAM FILM ANIMASI
}

\author{
Annisaa Nurjanah, Santi Sidhartani, \& Dendi Pratama \\ Program Studi Desain Komunikasi Visual \\ Fakultas Bahasa dan Seni, Universitas Indraprasta PGRI \\ Jl. Nangka No 58 C, Tanjung Barat, Jakarta 12530, Indonesia \\ annisaanurjanah.91@gmail.com
}

\begin{abstract}
Abstrak
Siti Walidah merupakan seorang pahlawan perempuan Indonesia yang berjuang untuk memperjuangkan hak-hak perempuan, terutama dalam bidang pendidikan dan kesempatan untuk mengemukakan pendapat di dalam suatu organisasi. Siti Walidah melawan arus demi mendapatkan kesempatan untuk bisa memberdayakan kaum perempuan di Indonesia. Pembahasan tentang karakter animasi ini menggunakan pendekatan kualitatif dengan metode semiotoka struktural, yaitu mendesain pesan melalui elemen visual garis, bentuk, tekstur, dan warna. Melalui perancangan film animasi ini, diharapkan dapat menumbuhkan ketertarikan dan memberikan gambaran kepada para generasi muda khususnya remaja perempuan dalam mengenal tokoh Siti Walidah sebagai pahlawan perempuan Indonesia.
\end{abstract}

Kata Kunci: Siti Walidah, film animasi, karakter

\begin{abstract}
Siti Walidah is an Indonesian female hero who struggles to fight for women's right, especially in the field of education aand the opportunity to express opinions within an organization. Siti Walidah against the flow in order to get the opportunity to be able to empower women in Indonesia. The discussion about this animated character uses a qualitative approach with structural semiotics method, namely designing messages through visual elements of lines, shapes, textures and colors. Through the design of this animated film, it is hoped that it can foster interest and provide an overview to the younger generation, especially teenage girls, in recognizing Siti Walidah characters as an Indonesian female hero.
\end{abstract}

Keywords: Siti Walidah, animated film, character

\section{PENDAHULUAN}

Siti Walidah, merupakan pahlawan perempuan yang erat kaitannya dalam perjuangan kaum perempuan dalam hal pendidikan dan hak perempuan untuk mengemukakan pendapatnya di dalam sebuah wadah organisasi. Siti Walidah merupakan pahlawan perempuan yang berusaha untuk memajukan kaum perempuan Indonesia, terutama di Kauman, tempat dimana ia dilahirkan, dibesarkan hingga wafatnya. Namun, menurut Purwaningsih, Wakil Kepala SMP 11, Jakarta Selatan menyatakan bahwa kurangnya minat anak sekarang terhadap sejarah.

Berdasarkan masalah tersebut peneliti akan memperkenalkan tokoh Siti Walidah melalui film animasi. Film animasi dipilih karena menurut Pusat Studi dan Penelitian (Center for the Study of Islam and Social Transformation) CISForm UIN Sunan Kalijaga dalam meyakini bahwa film animasi merupakan salah satu cara yang sangat efektif untuk menjangkau pemuda Indonesia 
dan animasi mudah diterima siapa saja, terutama kalangan remaja. Terlebih, kalangan remaja sangat rentan terhadap propaganda yang disebarkan melalui sosial media yang mengakibatkan mereka lupa akan sejarah negaranya.

Dalam sebuah film animasi pasti terdapat tokoh yang digambarkan sebagai pemeran dalam film tersebut. Proses perancangan karakter Siti Walidah ini didasarkan pada tokoh sejarah, proporsi tubuh manusia, dan digabungkan dengan data-data visual yang dapat membantu proses desain karakter tersebut.

Penelitian ini mendasarkan referensi pakaian yang digunakan oleh masyarakat Kauman di masa lalu. Penelitian ini bertujuan untuk mengenalkan dan mengembalikan ingatan tentang karakter pahlawan perempuan Siti Walidah kepada para generasi muda terutama perempuan agar mereka semakin mengenal para pejuang yang telah berkontribusi dalam kemerdekaan negaranya.

\section{METODE PENELITIAN}

Pendekatan kualitatif dalam penelitian ini digunakan untuk mengumpulkan data gambaran visual tokoh Siti Walidah, wawancara kepada narasumber yang memahami tentang Siti Walidah dan observasi. Metode semiotika, berisi teori pembacaan tanda. Semiotik adalah ilmu tentang tanda dan penggunaannya dalam berbagai hal analisis media untuk menghasilkan kode tanda yang berarti (Pratama, Wardani dan Akbar, 2017). Melalui metode ini, karakter Siti Walidah yang akan dibuat dapat dilihat sifat dan karakternya melalui desain karakter tersebut.

\section{HASIL DAN PEMBAHASAN}

Perancangan karakter Siti Walidah ini dilakukan untuk mendapatkan desain karakter yang sesuai dengan data visual yang didapatkan. Karakter ini akan digunakan untuk film animasi yang nantinya akan dibuat mengenai Siti Walidah. Karakter ini akan membantu penonton yang menikmati film animasi dapat mengetahui seperti apa sosok Siti Walidah dan bagaimana sifat yang dimilikinya melalui karakter animasi yang dibuat.

\section{Animasi}

Animasi adalah bentuk adaptif yang menarik dan luar biasa dari ekspresi audio visual yang sangat efektif dalam menggabungkan gambar bergerak dan suara bersama untuk menceritakan kisah dan menjelaskan ide-ide (Selby, 2013: 6). Hal ini berarti, animasi adalah suatu tampilan dari gabungan gambar-gambar yang digerakan serta ditambahkan suara untuk menghasilkan suatu karya yang dapat dinikmati melalui penglihatan. Animasi dapat menceritakan kisah dan ide-ide yang disampaikan secara lebih efektif.

Hal ini dapat disimpulkan bahwa, film animasi merupakan sarana yang digunakan untuk menyebarkan informasi yang disampaikan melalui gambar bergerak yang disertai dengan pemberian suara yang dimaksudkan untuk menguatkan isi dari pesan yang akan disampaikan.

\section{Karakter}

Menurut Pratama, Wardani dan Akbar (2017), kekuatan visual itu mampu membangun persepsi seseorang melalui elemen-elemen desain pada karakter visual. Sehingga dapat dikatakan bahwa seseorang dapat melihat dan berpendapat mengenai sesuatu hal melalui karakter yang ia lihat tersebut. Sedangkan menurut Fiky \& Lakoro (2016) menyatakan bahwa karakter merupakan elemen yang membuat suatu cerita patut untuk dibaca, didengarkan ataupun ditonton, dan dapat mengajak audiens untuk merespon secara emosional atas keberadaannya dalam cerita tersebut. Maka dari itu, karakter dalam suatu karya sangat diperlukan dan harus dibuat dengan menarik agar dapat memberikan sugesti kepada orang yang melihatnya untuk mempelajari ataupun mencari tahu tentang suatu karya yang dibuat. 


\section{Pembacaan Elemen Desain Dalam Karakter Visual Siti Walidah}

Pembacaan karakter dari Siti Walidah untuk film animasi ini akan dibuat secara deskriptif. Pada pembacaan karakter ini akan dijelaskan seperti pakaian yang dikenakan, ekspresi mata, wajah dan bentuk tubuh, serta tekstur dari pakaian yang digunakan.

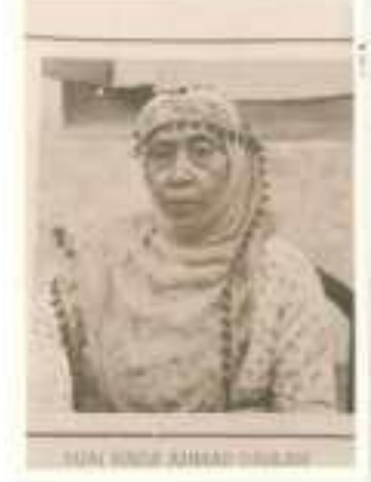

Gambar 1 KH. Ahmad Dahlan dan Siti Walidah

Sumber: Booklet KHA Dahlan-Widyastuti

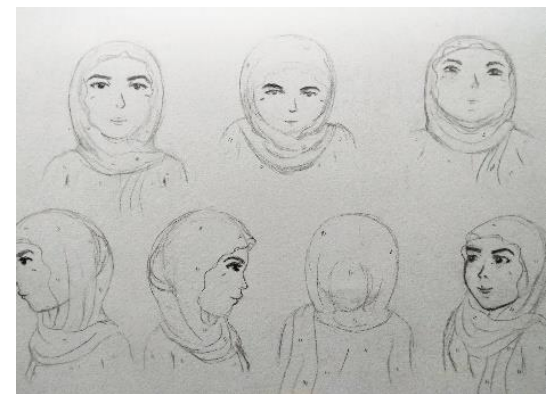

Gambar 2 Sketa manual karakter Siti Walidah

Sumber: Dokumen pribadi

Elemen desain dalam penelitian ini dirancang untuk membawa pesan kepada khalayak melalui elemen-elemen desain seperti bentuk, tekstur dan warna. Pada wajah dan tubuh, elemen bentuk dibuat berdasarkan data visual yang didapatkan yaitu foto Siti Walidah. Bentuk mata, wajah serta bibir menunjukan ketegasan dan ketenangan. Dalam penelitian ini, berusaha untuk menunjukkan perempuan yang kuat, gigih dan penyayang melalui bagian tubuh yang berisi dan tegap sesuai dengan data visual dari Siti Walidah. Dalam elemen tekstur, peneliti menyesuaikan motif batik sejarah sebagai simbol dari suku Jawa. Pada karakter kreasi, peneliti menggunakan warna-warna yang sesuai dengan keadaan saat itu untuk menggambarkan tokoh pahlaan di masa lalu. Demikianlah pembahasan mengenai pembacaan elemen desain dalam karakter Siti Walidah.

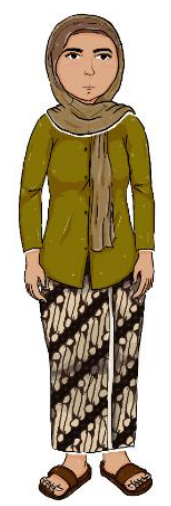

Gambar 3 Penggambaran karakter Siti Walidah Sumber: Dokumen pribadi 


\section{Elemen pada karakter Siti Walidah:}

1. Bentuk

Bentuk mata dari karakter Siti Walidah menggambarkan ketajaman dan ketenangan pandangan. Bentuk bibir dari Siti Walidah menggambarkan ketegasan dan lembut.

\section{Tekstur}

Teksur yang terdapat dalam karakter Siti Walidah terlihat pada baju yang dikenakannya dengan motif bunga dan kain batik motif Parang yang menjadi ciri khas batik Yogyakarta. Menggambarkan kedaerahan dan karakter dari Indonesia

3. Warna

Warna yang terdapat pada karakter Siti Walidah adalah warna-warna yang menggambarkan kesan masa lalu dengan warna dominan coklat dan abu-abu. Warna ini digunakan untuk membuat audiens dapat merasakan kesan kesejarahan tokoh ini.

\section{SIMPULAN}

Desain karakter visual Siti Walidah sebagai tokoh pahlawan perempuan Indonesia dalam film animasi dibentuk melalui elemen desain berupa bentuk, tekstur dan warna. Elemen-elemen desain yang digunakan, mampu menghasilkan tanda-tanda dari sifat dan karakter yang dimiliki Siti Walidah.

Studi ini bisa menjadi referensi dalam penerapan desain komunikasi visual dan juga bermanfaat untuk kepentingan nasional, terutama untuk mengingatkan akan sejarah Indonesia dan pengembangan desain karakter visual. Model desain karakter didasarkan pada data-data literatur maupun visual yang didapatkan mengenai Siti Walidah.

\section{DAFTAR PUSTAKA}

Anonymous. (2015). UIN Sunan Kalijaga Kampanye Islam Lewat Film Animasi. Republika.co.id. Diakses 17 Oktober 2018, diambil dari http://m.republika.co.id/amp/p31mpe382.

Fiky, M., \& Lakoro, R. (2017). Perancangan karakter serial animasi 3D "Sanggramawijaya" dengan studi archetype adaptasi literatur tokoh film action lokal Indonesia. Jurnal Sains dan Seni ITS, 5(2), 204-208.

Pratama, D., Wardani, W. G. W., \& Akbar, T. (2017). Designing visual character of Raden Wijaya as historical figure in visual novel. International Journal of Scientific \& Technology Research, 6(11), 207-210.

Selby, A. (2013). Animation. China: Laurence King Publishing Limited. 